\title{
Diverse teaching methods: How to approach to different levels of anxiety
}

\author{
Meleka Asotić, Ajša Bahović Latifović
}

\begin{abstract}
Introduction
Research onto the phenomena of language anxiety in foreign language communication has been present for almost four decades (Liu 2019). Despite decades of dealing with the topic of linguistic anxiety, professional literature is rich with a variety of understandings and theoretical settings (Tran 2012). However, the starting point of almost all researchers of language anxiety is a theory of Horwitz, Horwitz and Cope (1986) that formed the basis for the construction of a well-known instrument - the Foreign Language Classroom Anxiety Scale (FLCAS). In recent years, dealing with the phenomena of foreign language anxiety (FLA) has been evident. Not only have numerous articles testified to the factuality, but also publications, such as, New insights into language anxiety: Theory, Research and Educational Implications". The importance of this publication is not only illustrated by the fact that the authors of the texts are eminent experts who have been dealing with the FLA phenomenon for years, but also that the problem is addressed in a comprehensive way: through a theoretical discussion of Horwitz's classic research, through new empirical research on FLA and considering practical implications (Liu 2019). Moreover, the aforementioned publications, as well as numerous professional papers, confirm that FLA is not an abstract phenomenon but a real problem that today's students face (Tran 2012). In this regard, this research paper has focused on examining the level of linguistic anxiety of high school students by providing
\end{abstract}


an alternative way to measure FLA. Unlike the well-known FLCAS, the research work focused on designing a new measuring instrument - FLSAQ (Foreign language speaking anxiety questionnaire). The aim of the paper is not only to identify the extent of the anxiety problem but also to provide practical mechanisms to overcome this phenomenon. Having considered all the issues mentioned, our effort was set aside comprehension and provision of a general and universal view of the FLA phenomenon.

\section{Theory}

Most authors would probably agree that the pioneering work of Horwitz et al. (1986) is still a key theoretical basis for understanding the phenomenon of foreign language anxiety in a classroom environment. However, it is considered there are different understandings and definitions of FLA and that other authors have also made significant contributions to the development of this phenomenon. Perhaps utmost credentials for incentive and development the FLA concept go to McCroskey $(1970,1978)$ who defined the term „communication apprehension“. Communication apprehension is considered as the general anxiety associated with oral communication and associated with real or anticipated communication with others. Just a few years after McCroskey's work, the first definitions of the FLA emerged. Clement (1980) thought that FLA should be defined in terms of feelings, self-esteem and self-confidence. That's why he thought the FLA belonged to the field of learners' psychology (Clement 1980). Horowitz et al. (1986) seem to embrace Clement's idea by defining FLA as a construct associated with self-perceptions, beliefs, feelings, and behaviours. In their view, FLA is a unique type of anxiety associated with learning a foreign language in class and different from other types of anxiety (Horowitz et al. 1986). MacIntyre and Gardner (1994) and Zhang (2001) considered FLA as a (psychological) sense of persons' tension while learning a foreign language. Mihaljevic Djigunovic (2002) considers FLA to be a short-term excruciating condition that accompanies feelings of discomfort, nervousness and insecurity. Namely, this feeling is accompanied by certain physiological reactions such as rapid heart rate, chest pressure, rapid breathing, etc. (Popović-Babić, Apostolović, and Biskupljanin 2007). Almost all definitions describe FLA as a tense and uncomfortable condition similar to general anxiety. Therefore, understanding FLA also implies a clear distinction from general anxiety and other specific anxiety states, as it is a unique type of anxiety that is connected to specific situations, while general anxiety is related to all situations. (Horowitz 
et al. 1986).Also, some authors find it necessary to emphasize the difference between anxiety as a trait and as a state (Salehi and Marefat 2014). FLA is rather state anxiety (Brown 2000), and this is supported by research that has found that trait anxiety has no predictive value in second language achievement (MacIntyre and Gardner 1991). In that context, anxiety as a personality trait should be distinguished from one that binds to specific situations (Králová 2016). FLA should be distinguished from general academic anxiety as well. Thus, it will certainly happen that students who have general anxiety feel FLA, but it is evident that some students do not feel anxious about other school subjects except in learning a foreign language (Tran 2012). Considering language anxiety and looking for a way to make the terminological distinction, Horwitz et al. (1986) talked about the FLA components: communication apprehension, test anxiety and fear from the negative evaluation. While communication apprehension is related to the anxiety experienced in interaction (speaking and listening to others), anxiety on testing is a form of performance-related anxiety, and fear of negative evaluation is related to the students' perception of how others (teacher and classmates) can influence on his or her language ability (Horowitz et al. 1986). Based on the above-mentioned comments, Horwitz et al. (1986) constructed the instrument FLCAS, which measures anxiety levels taking into account data on negative performance expectations and social comparisons, psychophysiological symptoms and avoidance behaviours (Tran 2012). However, some authors have shown that the anxiety test is rather associated with general anxiety and therefore not specifically associated with foreign language learning (MacIntyre and Gardner 1989; Aida 1994). Understanding the specifics of the FLA, this concept also requires considering the causes. Young (1991) cites several causes of the occurrence of FLA in a classroom situation, which are: personal and interpersonal anxiety, learner beliefs about language learning, instructor beliefs about language teaching, instructor-learner interactions, classroom procedures and language testing. Von Wörde (2003) believes that causes should be sought in the inability to comprehend, negative classroom experiences, pedagogical practice, correction of mistakes and native speakers. The causes of FLA indicate the problems lie not only inside the student, but also in sources outside the individual, i.e. in the way of interaction between the student and the professor, in the procedures and the method of assessment of English, in pedagogical practice, and similar. 


\section{Methodology}

\section{Participants}

The research has involved 100 second and fourth-grade high school students located in the Sanjak region. One of the conditions for the selection of students in the research was the students had been attending English classes in five years' continuation. The study involved 54 female and 46 male students. Students who participated in the qualitative part of the research were not included in the quantitative part of the research. The first (qualitative) survey's part involved 15 students. The students were 17 years old, and comparing gender, 6 male and 9 female students were included. In the second (quantitative) part of the survey, 85 students participated, concerning the availability within classes. According to gender, 45 female students and 40 male students participated.

\section{Instruments}

A new FLSAQ questionnaire was constructed to survey the second phase. The FLSAQ is intended to assess anxiety during students' foreign language speech. The aforementioned questionnaire contains 20 items that are formulated based on data obtained through the qualitative part of the research. Items are assessing the thoughts, behaviours, and feelings of a student when speaking a foreign language during school class. The FLSAQ's format is five-level Likert item (from completely inaccurate to completely accurate). The reliability (internal consistency) of the instrument was also calculated and is $\alpha=.927$, indicating high reliability. The FLSAQ validity data is presented in the results section. In addition to the FLSAQ, the FLCAS instrument was also used (Foreign Language Classroom Anxiety Scale) (Horwitz et al. 1986). The FLCAS contains 33 items and is in the form of a 5-point Likert scale ranging from "completely disagree" to "completely agree". The primary purpose of FLCAS was to measure speech-language anxiety in the classroom situation (Horwitz et al. 1986), and later, in some studies, it was used to assess anxiety in other language skills than just speech (Saito, Horwitz and Garza 1999; Cheng 2002). Prior research has confirmed the high reliability of the instrument $(\alpha=.940)$ (Aida 1994) and this research confirmed the same as Kronbach's alpha coefficient is .923. FLCAS was used in this study to determine the construct convergent validity. Oral performance measures (OPM) were formulated to determine the criterion validity of the FLSAQ, and to assess whether 
and to what extent measured anxiety affects speech. OPM is a scale that contains grades 1 to 5 (grade 1 is the lowest and indicates the worst English language proficiency, while grade 5 is the best foreign language proficiency). The level of speaking language was assessed by grade, using the following criteria: vocabulary, sentence coherence - SVOMPT and grammar in constructing a sentence.

\section{Research design}

The research is of qualitative-quantitative type and was conducted in two phases. The research first phase was a qualitative type and involved conducting interviews. The interview was semi-structured. The aim of the interview was to get an answer to how pupils feel during second language speaking (their experience with anxiety) and what the best way to decrease anxiety is. The second phase of the research was of a quantitative type. In this phase, students were responding on FLSAQ and FLCAS items. Before selecting the examiner to participate in the second (quantitative) phase of the survey, foreign language teachers evaluated the respondent's proficiency in the language by the OPM scale.

\section{Data analysis}

Descriptive measures (arithmetic mean, standard deviation, frequency and percentages) were used to assess the level of anxiety in students in the second phase of the study. Correlation and factor analysis was applied to determine the constructive and criterion validity of FLSAQ. Parallel analysis was used as the criterion for determining the final number of factors underlying the FLA. Parallel analysis was conducted using SPSS syntax for parallel analysis (O'Connor, 200o). In the qualitative part of the research, information on respondents anxiety reactions during the English language class were recorded. In the end, the answers were summarized in several categories and only those that were repeated mostly by all respondents were presented and taken into account for FLSAQ design.

FLSAQ total score is calculated by the sum of all respondents' responses to items. All items had equal importance in calculating the total score. Before calculating the FLSAQ total score, negatively stated items are transformed in positively stated items. 


\section{Results}

As noted in the methodology, the research was conducted in two phases. In the first phase, an interview was conducted with 15 high school students. The aim of the interview was to obtain information on the questions of feeling anxiety during the speech in a foreign language and how the anxiety manifests. Respondents also described conditions opposite to anxiety in order to better understand the conditions to be pursued when learning a foreign language. The data are presented in Table 30.

\section{Table 30: Descriptions of anxiety reactions and opposite reactions to anxiety in foreign language learners.}

\begin{tabular}{lll}
\multicolumn{1}{c}{ Feelings } & \multicolumn{1}{c}{ Thoughts } & \multicolumn{1}{c}{ Behaviour } \\
$\begin{array}{l}\text { Fear } \\
\text { Panic } \\
\text { Confusion } \\
\text { Tension } \\
\text { Nervousness } \\
\text { Discomfort }\end{array}$ & $\begin{array}{l}\text { Worry about what others think } \\
\text { Worry not to be ridiculous } \\
\text { Thoughts blockade } \\
\text { The belief that everything must } \\
\text { turn out without mistakes }\end{array}$ & $\begin{array}{l}\text { Silence } \\
\text { Avoiding conversation } \\
\text { Having the desire to abandon } \\
\text { the class }\end{array}$ \\
$\begin{array}{l}\text { Contrary to anxiety } \\
\text { Fear in terms of tension, tre- } \\
\text { mors, discomfort exists but it } \\
\text { lasts briefly and quickly can be } \\
\text { overcome }\end{array}$ & $\begin{array}{l}\text { is grammatically correct } \\
\text { it does not matter if everything } \\
\text { the challenge is to learn } \\
\text { something new }\end{array}$ & $\begin{array}{l}\text { Concentrated on speech, ac- } \\
\text { cepting communication, re- } \\
\text { laxed in speech }\end{array}$ \\
\hline
\end{tabular}

By analyzing the data in Table 30 , it can be found that the descriptions of reactions during foreign language speech can be classified into three categories: thoughts, feelings and behaviours. In addition to the fact that the respondents felt fear, panic and nervousness during the foreign language speech, during the interview it could be heard that there were other reactions associated with and represent a manifestation of anxiety. For example, respondents stated that they: worry about what others will think, think they have to utter everything perfectly and without mistake, because otherwise they will be ridiculed, need to interrupt communication or remain silent, and those reactions go to such an extent they want to leave class. On contrary to anxiety reactions, students feel they would be more successful in speaking a foreign language: if they felt more relaxed, if they did not think what others thought of their speech, but were only oriented towards speech and when they stopped worrying that everything had to be spoken perfectly and correctly. During the interview, respondents were also asked 
questions about mechanisms to reduce anxiety in foreign language speaking in a classroom situation. Respondents' answers can be classified into several categories:

1. The professor must be less demanding, be patient, have more understanding for the mistakes made in the speech and must punish pupils who mock others while they speak in a foreign language.

2. Some of the pupils think anxiety is conditioned by poor knowledge of vocabulary and grammar of a foreign language, so anxiety will be decreased when pupils start to learn more.

3. Some pupils think that anxiety originates from personality and has little to do with what is happening in the classroom, so there are not ways to reduce anxiety.

So, in the pupils' opinion, anxiety will decrease if professors change their way of dealing with students and if students learn more. Some pupils think that anxiety is a matter of personality and therefore there is no way to solve the problem.

Interview data were used to formulate FLSAQ items. To verify construct validity of the FLSAQ, exploratory factor analysis was applied and the degree of association with another instrument - FLCAS in order to determine if different instruments, measuring the same construction, were correlated (Faljgelj 2009; Taherdoost 2016). At the beginning of the analysis, the items communalities were checked. According to some authors, all items whose communalities is lower than .32 (Tabachnick and Fidell 2014) and .30 (Field 2013) should be excluded from further analysis. In this regard, item no 2 are excluded from further analysis „When I speak English on class, I'm completely relaxed“ and item no 20 "I'm glad if the professor invites me to talk in English“. The justification for applying EFA is established by the values of Bartlett's test of sphericity $\left(\chi^{2}=1735.81, \mathrm{df}\right.$ $=153, \mathrm{p}<.001)$ and Kaiser-Meyer-Olkin Measure of Sampling Adequacy $(\mathrm{KMO}=.872)$. EFA was performed using the principal axis method with promax rotation. By applying Horn's parallel analysis (Çokluk and Koçak 2016) it was found that at the base of the FLSAQ lies one factor (see Table 31). 
Table 3r: Tabular view of applied Horn parallel analysis with data permutation $(K=300)$.

\begin{tabular}{ccc} 
Factor & $\begin{array}{c}\text { Eigen values } \\
\text { of the actual data }\end{array}$ & $\begin{array}{c}\text { Eigen values } \\
\text { of the simulative data }\end{array}$ \\
\hline 1. & 5,29 & 1,63 \\
\hline 2. & 1,46 & 1,51 \\
\hline 3. & 1,02 & 1,35 \\
\hline
\end{tabular}

Therefore, based on the parallel analysis, it can be concluded the presence of one factor in the structure of FLSAQ, which explains $57.40 \%$ of the total variance. An outline of the single-factor items structure is given in Table 32 .

Table 32: Correlation between items and factor.

\begin{tabular}{|c|c|c|}
\hline No & Items & $\mathrm{R}$ \\
\hline 1. & I worry what others think about my oral performance in English. & .909 \\
\hline 5. & I'm wondering if others will mock me. & .897 \\
\hline 11. & I keep quiet because if I say something, I can be mocked. & .887 \\
\hline 15 . & I feel constant tension. & .852 \\
\hline 7. & $\begin{array}{l}\text { I feel panic because I cannot remember the words or I do not know how to say } \\
\text { something. }\end{array}$ & .778 \\
\hline 9. & I'm completely confused. & .775 \\
\hline 3. & I'm blocking myself and I do not know what to say. & .721 \\
\hline 16. & I do not care what others think about my speaking. & .701 \\
\hline 8. & I do not think what others will think or being ridiculed. & .683 \\
\hline 12. & I am completely self-confident. & .605 \\
\hline 19. & I think that everything has to be correct and perfect, and that makes me confused. & .543 \\
\hline 13. & I'm afraid what the professor will say and if (s)he corrects me. & .539 \\
\hline 17. & I think that it's better to avoid my English class. & .500 \\
\hline 4. & $\begin{array}{l}\text { Although I feel anxiety (fear, nervousness, tension), it lasts shortly and it is quic- } \\
\text { kly overcome. }\end{array}$ & .456 \\
\hline 10. & I do not have a problem at all to say anything even if it's incorrectly said. & .433 \\
\hline 18. & I am completely concentrated on speech and I do not think about anything else. & .417 \\
\hline 14. & I think that I need to learn something new even if I make a mistake. & .403 \\
\hline 6. & I speak English as my native language. & .399 \\
\hline
\end{tabular}

It is of a notion in Table 32 that the items having the highest correlations with the factor related to the problem of speaking a foreign language of students in front of their peers. In further analysis, the association of summarizing scores on FLSAQ and FLCAS was checked. Pearson correlation coefficient is $\mathrm{r}=.656(\mathrm{p}<.01)$, which confirms the good construct validity of the FLSAQ. Critical validity was also checked, that is, whether FL$\mathrm{SAQ}$, which measures anxiety, indicates that anxiety in English speaking 
has an effect on speech performance. A mark on OPM was taken as a measure of assessment of spoken English (oral performance measure). The regression coefficient is $\mathrm{r}=-.489(\mathrm{p}<.01)$ and $\mathrm{R}=.239$. When the basic metric characteristics of FLSAQ (reliability and validity) were verified, further analysis determined the scores (degree of anxiety) distribution of the subjects on FLSAQ. Since the total score can range from 20 to 100 , the test scores were grouped into several categories: 20 to 39 (slight anxiety), 40 to 59 (moderate anxiety), 60 to 79 (heightened anxiety), and 80 to 100 (high anxiety). The distribution of anxiety on the sample can be viewed in Graph 1.

\section{Pupils anxiety level}

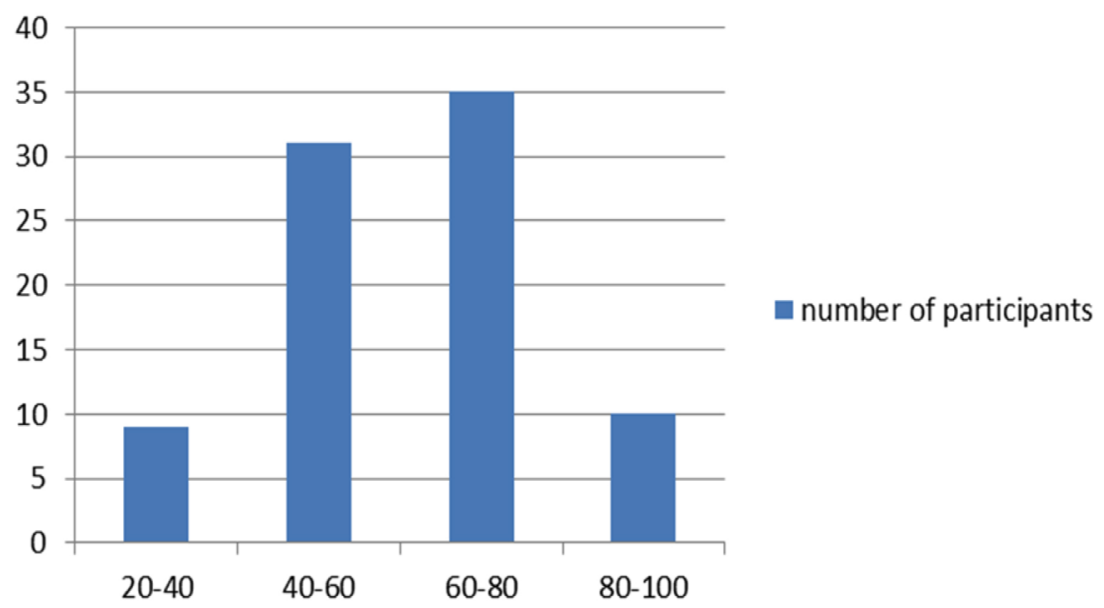

Figure I3: Distribution of anxiety during foreign language speaking.

Descriptive measures were also calculated $(M=58.32, S=14.23$, Skewness $=-.068$, Kurtosis $=-.554$ ), indicating that anxiety levels were generally moderate to heightened and it was observed that about $65 \%$ of respondents (greater summation score than 60 on FLSAQ) had increased and high anxiety in speaking English. Skewness and kurtosis values indicate that distribution is moderately negative skewed and platykurtic.

\section{Discussion}

From the research qualitative phase, students denote many obstacles they face with when learning a foreign language. As noted in previous researches, anxiety can be triggered by a real classroom situation or be anticipated 
by past negative experiences, for instance. Regardless of the multiplicity of causes of FLA, this research shows that anxiety reactions (manifestations) can be classified into thoughts, feelings, and behaviours. The above classification is different from the one presented by Horowitz et al. (1986), who perceives three dimensions in the FLA concept (communication apprehension, test anxiety and fear from negative evaluation). Unlike Horowitz et al. (1986), in this paper, anxiety in a classroom situation is viewed as a psychological construct that has its manifestation rather than an association with causes such as fear of negative evaluation or attachment to a particular situation such as anxiety test. Factor analysis results suggest that FLA is a one-dimensional rather than a multidimensional concept, as claimed by Horwitz et al. However, it should be kept in mind that the analysis in this paper was conducted on a compact sample of students. Therefore, the following analyzes must confirm the un-dimensionality of the FLA on a larger sample and by applying confirmatory factor analysis (CFA). The analysis showed that the most eminent problem with learning English in school conditions is that students speak the language in front of their peers. This is also set out by the results of Koch and Terrell's (1991) study, which shows that most students experienced the greatest anxiety when communicating in front of others. Von Wörde (2003) also discusses this phenomenon, explaining that negative classroom experiences have a great influence on learning a foreign language, due most students feel anxious when speaking in a classroom situation, fearing the opinions of peers as well as teachers. That's why students say that one way to reduce anxiety must come from a teacher who has to be sensitive and recognize anxiety and then work on the relationship teacher - pupils and between pupils themselves. Students state that the reason for anxiety is not only related to the problem of speaking in front of peers but also in poor knowledge of a foreign language. Therefore, the problem can be solved if students learn more and thus become more confident in themselves and their foreign language skills. There are also opinions that anxiety is not related to either the school situation or poor knowledge of a foreign language, but rather that it is a problem of students' personality. It should be bear in mind that most authors have defined FLA as state anxiety and not trait anxiety (Brown, 2000) and that even studies have shown that trait anxiety has no predictive value in second language achievement (MacIntyre and Gardner 1991). The study showed that FLA was presented at students' oral performance since $65 \%$ of students have got high-levelled anxiety during speaking a foreign language. Also, the nega- 
tive correlation between speaking foreign language anxiety and oral performance confirms that anxiety is an influential factor and interferes with foreign language speech.

\section{Conclusions}

The research provided a new valid and reliable instrument for measuring speaking foreign language anxiety - FLSAQ. In spirit to confirm FLSAQ validity and reliability, future researches have to conduct studies using the mentioned instrument on a larger sample and by applying confirmatory factor analysis. Unlike FLCAS, the FLSAQ provides a new perspective on the concept of FLA, which is not a cause-oriented but a manifestation of anxiety. The research also confirms that FLA is a serious problem and an obstacle to successfully mastering a foreign language. Therefore, the practice should focus on ways to reduce anxiety in foreign language speech. One way is certainly to raise awareness that teachers need to recognize FLA and work on improvement student-professor relationships. There is also a belief that FLA is an unsolvable problem because it is more a matter of personality rather than the situation. And that is why the question may be asked if it is time to use some psychological tool (meditation or stress-reducing techniques) in a classroom situation. So, that is the reason why new empirical research is needed and which would not only aim to determine the extent of FLA expression but to give evidence for supporting effects of decreasing anxiety techniques and methods.

\section{Literature}

Aida, Yukie. "Examination of Horwitz, Horwitz and Cope's construct of foreign language anxiety: The case of students of Japanese," The Modern Language Journal 78, no. 2 (1994): 155-168. doi: 10.2307/329005.

Brown, Douglas H. Principles of Language Learning and Teaching. New York: Pearson Education, 2000.

Cheng, Yuh-show. "Factors associated with foreign language writing anxiety." Foreign Language Annals 35, no. 5 (2002): 647-656.

Clément, Richard. "Ethnicity, contact, and communicative competence in a second language." In Language: Social psychological perspectives, edited by Howard Giles, William P. Robinson, and Philip M. Smith, 147--154, Oxford: Pergamon Press, 1980. 
Çokluk, 冈may, and Duygu Koçak. “Using Horn’s Parallel Analysis Method in Exploratory Factor Analysis for Determining the Number of Factors." Educational sciences: theory \& practice 16, no. 2 (2016): 537-551.

Fajgelj, Stanislav. Psihometrija: metod i teorija psihološkog merenja. Beograd: Centar za primenjenu psihologiju, 2009.

Field, Andy. Discovering Statistics using SPSS. 4th ed. London: SAGE, 2013.

Honggang, Liu. "New Insights into Language Anxiety: Theory, Research and Educational Implications.” ELT Journal 73, no. 1 (2019): 105-107.

Horwitz, Elaine, Michael B. Horwitz, and Joann Cope. "Foreign language classroom anxiety.” The Modern Language Journal 70, no. 2 (1986): 125-132.

Koch, A. S., and T. D. Terrel. "Affective reaction of foreign language students to Natural Approach activities and teaching techniques." In Language anxiety: From theory and research to classroom implication, edited by Elain Horwitz and Dolly J. Young, 109--126, Englewood Cliffs: Prentice Hall, 1991.

Králová, Zdena. Foreign Language Anxiety. Nitra, Slovakia: Univerzita Konštatina Filozofa v Nitre, 2016.

MacIntyre, Peter D., and Robert. C Gardner. "Anxiety and second language learning: Toward a theoretical clarification.” Language Learning 39, no. 2 (1989): 251-75.

MacIntyre, Peter D., and Robert. C Gardner. "The subtle effects of language anxiety on cognitive processing in the second language." Language Learning 44, no.2 (1994): 283-305.

McCroskey, James C. "Measures of Communication-Bound Anxiety." Speech Monographs 37, no.4 (1970): 269-277.

McCroskey, James C."Validity of the PRCA as an index of oral communication apprehension." Communication Monographs 45, no. 3 (1978): 192-203.

Mihaljević Djigunović, Jelena. Strah od stranog jezika. Zagreb: Naklada Ljevak, 2002.

O'Connor, Brian P. "SPSS and SAS programs for determining the number of components using parallel analysis and Velicer's MAP test." Behavior research methods, instrumentation, and computers, no. 32 (200o): 396-402.

Popović-Babić, Danica, Mirjana Apostolović, and Bogdan Biskupljanin. "Psychological Aspects of Fear Because of pain in stomatological offices." $\mathrm{Me}$ dicina danas, 7/8 (2007): 423-428.

Saito, Yoshiko, Elaine K. Horowitz, and Thomas J. Garza. “Foreign Language Reading Anxiety.” The Modern Language Journal 83, no. 2 (1999): 202-218. 
Salehi, Masoomeh, and Fahimeh Marefat. “The Effects of Foreign Language Anxiety and Test Anxiety on Foreign Language Test Performance." Theory and Practice in Language Studies 4, no. 5, (2014): 931-940.

Tabachnick, Barbara G., and Linda S. Fidell. Using Multivariate Statistics. 6th ed. Harlow: Pearson, 2014.

Taherdoost, Hamed. "Validity and Reliability of the Research Instrument; How to Test the Validation of a Questionnaire/Survey in a Research." International Journal of Academic Research in Management 5, no. 3 (2016): 28-36.

Tran, Trang T. T. "A review of Horwitz, Horwitz and Cope's theory of foreign language anxiety and the challenges to the theory. "English Language Teaching 5, no.1 (2012): 69-75.

von Wörde, Renée. "Students' perspectives on foreign language anxiety." Inquiry 8, no. 1 (2003): 21-40.

Young, Dolly J."Creating a low-anxiety classroom environment: What does foreign language anxiety research suggest?" The Modern Language Journal 75 , no. 4 (1991): 426-437.

Zhang, Jun L. "Exploring variability in language anxiety: Two groups of PRC students learning ESL in Singapore.” RELC Journal 32, no. 1 (2001): 73-94. 